\title{
TRATAMENTO E CARACTERIZAÇÃO FÍSICO-QUÍMICA DO ÓLEO DE FRITURA E SEBO BOVINO PARA DESENVOLVIMENTO DE BLENDAS LÍQUIDAS CAPAZES DE SEREM DESTINADAS PARA PRODUÇÃO DE BIODIESEL ETÍLICO.
}

Sandro Martins de Oliveira ${ }^{1}$

Juan Carlos Dalcolle ${ }^{2}$

\section{Nehemias Curvelo Pereira ${ }^{3}$}

RESUMO: Devido ao crescente interesse por novas fontes energéticas, o biodiesel tem ganhado grande destaque dentre as fontes de energia limpa. Esse biocombustível pode ser produzido tanto com óleos de origem vegetal como de origem animal; duas matérias prima que tem ganhado a atenção de pesquisadores é a utilização do sebo bovino e óleo de fritura (cocção). Estes produtos são considerados resíduos pela sociedade e em grande parte são descartados, o que gera um grande problema para a natureza. Porém se isoladas possuem algumas desvantagens, juntas podem ser de grande beneficio. Por isso a ideia de melhorar estas características indesejadas utilizaremos a produção de blendas. A mistura dos dois componentes pode resultar em uma matéria-prima com baixo custo de produção, associado a um baixo custo de tratamento, barateando a produção de biodiesel associado à qualidade do mesmo. Este trabalho baseia se na produção de

\footnotetext{
${ }^{1}$ Acadêmico de Mestrado em Bioenergia, departamento de Engenharia Química, na Universidade Estadual de Maringá - UEM, Maringá - Paraná. Bolsista CAPES. osordnas@yahoo.com.br.

2 Acadêmico do Curso de Engenharia Química na Universidade Estadual de Maringá - UEM, Maringá - Paraná. Bolsista $\mathrm{PIBIC/CNPq}$. juandalcolle@hotmail.com.

${ }_{3}$ Orientador, Professor Doutor do Curso de Engenharia Química na Universidade Estadual de Maringá - UEM, Maringá Paraná. nehemiascp@yahoo.com.br
} 
blendas de sebo mais cocção no estado líquido e assim encontrar uma matéria-prima ideal e viável para produção de um biocombustível de qualidade.

Palavras-chave: Resíduos. Blendas. Resíduos.

\section{INTRODUÇÃO}

Atualmente a necessidade de criação de novas fontes energéticas limpas e renováveis vem ganhando cada vez mais destaque no mundo, onde o objetivo deixou de ser somente - lucro e passou a levar em consideração a natureza e como podemos reduzir os impactos sobre ela, o chamado desenvolvimento sustentável. Segundo Santini;Marconato (apud STIGLITZ, 2007): "O conceito de desenvolvimento sustentável emerge na busca de se associar a eficiência econômica com a prudência ecológica”.

É nessa busca que pode ser observado diversas pesquisas para a criação de novas fontes energéticas, dentre elas estão os biocombustíveis. O Brasil é um país avançado na utilização dessas novas formas, tendo como principais biocombustíveis o etanol, produzido a partir da cana-de-açúcar, e em crescimento o biodiesel, produzido de biomassa.

O biodiesel pode ser produzido de diversos óleos, tanto vegetais como animais, dentre esses óleos se destacam o óleo de soja, em sua grande maioria, e o sebo bovino. Porém em pequena escala existe uma produção derivada de diversos óleos que cada vez vem ganhando mais destaque em estudos com a finalidade de encontrar matérias primas que reduzam o custo de produção e aumentem a produtividade.

Uma das apostas para reduzir estes custos associados a uma consciência ambiental é a utilização do sebo bovino e óleo de fritura (cocção). Estes dois produtos são considerados resíduos pela sociedade e em grande parte são descartados, o que gera um grande problema para a natureza.

A utilização do sebo se tornaria uma fonte de emprego e renda, pois agregaria valor a este resíduo, que como pode ser visto, hoje é responsável pela produção de $16,1 \%$ do biodiesel nacional (ANP, fevereiro de 2010).

Já o óleo de fritura é um resíduo gerado em grande quantidade nas residências industrias e comércios alimentícios com um grande poder de poluição, 1 litro desse resíduo pode contaminar até 1.000 .000 de litros da água. Uma alternativa de destinação 
seria o biodiesel, onde impulsionaria a reciclagem, geraria empregos e renda, agregando valor ao produto e ainda diminuindo o custo do biocombustível produzido, já que esse produto não requer grandes tratamentos.

Mas assim como esses produtos tem suas vantagens, também apresentam suas desvantagens, e é para melhorar as características indesejadas que utilizamos a produção de blendas. Uma mistura dos dois componentes pode resultar em uma matéria prima com baixo custo de produção, associado a um baixo custo de tratamento, deste modo barateando a produção de biodiesel, associado à qualidade do mesmo.

Atualmente, o desenvolvimento de processos contínuos envolvendo blendas com sebo bovino é uma linha de pesquisa promissora (TARAVUS et al., 2009; MORAES et al., 2008). Para garantir esta, é necessária a caracterização das blendas produzidas para determinar a que apresenta as melhores características para a produção de um biocombustível aceito pela Portaria 042/2004 da ANP.

Tendo a matéria-prima na quantidade e abundância que temos, o nosso objetivo é desenvolver processos de aproveitamento de subprodutos, para aumentar a eficiência energética por unidade de área e na transformação, de forma a poder reduzir custos e ter, a médio e longo prazo, competitividade na produção do biodiesel em todas as regiões do país.

A produção do biodiesel precisa responder as questões socioambientais e de desenvolvimento sustentável. Cuidado para não degradar o ambiente ou deslocar a produção de alimentos, que dê oportunidade de emprego digno e justo, e seja rentável do ponto de vista econômico-financeiro, são as maiores preocupações quando se trata de biocombustíveis. É preciso não apenas aumentar a produtividade, mas aprimorar as variedades das matérias-primas existentes. Fornecimento de produtos com qualidade.

Segundo levantamento da comissão Europeia de Energia, todo petróleo do mundo acabará em 2047 se for consumido se maneira desenfreada como atualmente. Devido a este, e outros motivo existe um crescente interesse pela produção de biocombustíveis nas últimas décadas. Este novo mercado apresenta uma gama de vantagens com caráter ambiental, social e econômico.

O Brasil é um país de destaque nesse âmbito com grande capacidade de produção, em razão de seu tamanho e a vasta quantidade de matérias-primas que possui. 
Dentre essas, destaca-se o sebo bovino proveniente do grande rebanho, o segundo maior do mundo, que proporciona uma produção anual de 200.000 toneladas do produto, sendo que o mesmo não possui um destino final adequado, acabando como resíduos sem utilização. Considerando a alta produção e o baixo custo deste, se destaca como uma boa matéria-prima, porém com um grande problema, o alto índice de acidez.

Outra matéria-prima com as mesmas características comerciais e econômicas é o óleo de fritura. Este produto é um resíduo, o que lhe acarreta um baixo custo, estando disponível em grandes quantidades. Como no caso do sebo, ele não possui destino final, sendo que a maior parte do que é reutilizado é para fabricação de sabão, o restante é descartando contaminando rios, solos e lenções freáticos. Uma de suas maiores diferenças para o sebo bovino é o índice de acidez considerado baixo se comparado ao mesmo, porém também apresenta características não muito desejáveis para a produção do biodiesel.

Com o intuito de fazer a correção dessas características indesejáveis são produzidas blendas, neste caso, de duas matérias-primas abundantes no país, de baixo custo e que são responsáveis por grandes problemas ambientais quando descartadas sem controle, como normalmente ocorre. A utilização desses resíduos na produção de biodiesel seria uma forma de agregar valor aos mesmos, deste modo impulsionando sua reciclagem e originando novos postos de empregos responsáveis por recolher, tratar e distribuir para as indústrias interessadas no produto.

As blendas produzidas objetivam ser uma mistura ideal para a produção de biodiesel, deste modo associando qualidade do biocombustível ao baixo custo de produção e todas as vantagens econômicas, sociais e ambientais pela utilização do sebo bovino e óleo de fritura como matéria prima.

Sendo assim este trabalho teve como objetivo desenvolver e realizar a caracterização de blendas líquidas capazes de serem utilizadas como matéria-prima para produção de biodiesel possuindo eficiência similar ou superior do que as utilizadas atualmente.

\section{DESENVOLVIMENTO}


O processo de produção e caracterização das blendas é composto das seguintes etapas: preparação da matéria-prima, caracterização do óleo e do sebo, produção das blendas e caracterização das blendas liquidas.

As matérias-primas passaram por tratamento e filtragem antes da caracterização. O sebo $(1000 \mathrm{~mL})$ foi dissolvido em $800 \mathrm{~mL}$ de éter de petróleo. A solução foi filtrada para remoção do material sólido e o solvente destilado em rotavapor a $50^{\circ} \mathrm{C}$ sob vácuo $(-700$ $\mathrm{mmHg}$ ). Já o óleo de fritura após ser filtrado foi submetido em um sistema montado com um Kitassato sobre uma chapa aquecedora acoplado a uma bomba á vácuo, para homogeneização e secagem. Como mostra figura 1.

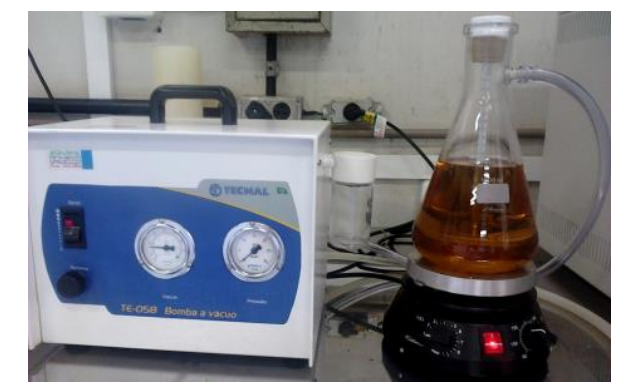

Figura 1: Homogeneização e secagem do óleo de fritura

A caracterização do óleo obteve-se a partir das analises, densidade feita pelo Densímetro digital Anton Paar modelo DMA 5000, Teor de Umidade pelo método ASTM D - 4377, Teor de Acidez método AOAC-940-28, Índice de saponificação pelo método AOCS Cd 3-52, Composição em ácidos graxos (cromatografia em fase gasosa). As blendas foram formadas em diferentes proporções para a obtenção da razão molar adequada AG:TG (ácidos graxos:triglicerídeos) em $50 \mathrm{~g}$. As mesmas foram levadas por 1 hora em freezer a $-5^{\circ} \mathrm{C}$ seguidas de 24 horas a $25^{\circ} \mathrm{C}$, após este período, as misturas que permaneceram em estado liquido foram definidas como as misturas ideais, o que possibilitou a realização da reação de transesterificação em catalise ácida, sendo utilizado o ácido sulfúrico como catalisador.

A produção de biodiesel é influenciada pelas propriedades físico-químicas do óleo. Apesar de não existir uma especificação oficial para os óleos e gorduras, dos quais são produzidos os biocombustíveis, estudos revelaram que altos índices de acidez e umidade, reduzem o rendimento da reação (CANAKCI, 2001). Inicialmente, foi realizada a 
cromatografia em fase gasosa para identificar os ácidos graxos presentes, obtendo resultados de acordo com a tabela 1 . Conforme o encontrado na literatura, as matériasprimas apresentam como ácidos graxos predominantes no óleo e no sebo respectivamente, Ácido Linoleico (C18:2n6c) e Ácido Oleico (C18:1n9c) .

Tabela 1. Cromatografia em fase gasosa.

\begin{tabular}{lccc}
\hline \multicolumn{1}{c}{ Óleo de fritura } & \multicolumn{3}{c}{ Sebo bovino } \\
\hline \multicolumn{1}{c}{ àcido graxo } & $\%$ & àcido graxo & $\%$ \\
Ácido mirístico (c14:0) & 0,4 & Ácido mirístico (c14:0) & 1,4 \\
Ácido palmítico (c16:0) & 11,6 & Ácido palmítico (c16:0) & 21,1 \\
Ácido palmitoleico (c16:1) & 0,5 & Ácido palmitoleico (c16:1) & 5,5 \\
Ácido esteárico (c18:0) & 3,6 & Ácido margárico (c17:0) & 1,2 \\
Ácido oleico (c18:1n9c) & 22,4 & Ácido esteárico (c18:0) & 26,3 \\
Ácido linoleico (c18:2n6c) & 51,7 & Ácido oleico (c18:1n9c) & 42,2 \\
Ácido linolênico (c18:3n3) & 8,9 & Ácido linoleico (c18:2n6c) & 2,3 \\
Ácido Erúcico (C22:1n9) & 0,9 & & \\
\hline
\end{tabular}

Os resultados na Tabela 2, ilustram que o índice de acidez e o teor de umidade no óleo de fritura estão abaixo do limite considerado aceitável para produção de biodiesel (2 $\mathrm{mg} \mathrm{KOH} / \mathrm{g}$ óleo e 0,5 \%, respectivamente, segundo Portaria 042/2004 da ANP).

Tabela 2. Caracterização das Matérias-primas.

\begin{tabular}{lcc}
\hline \multicolumn{1}{c}{ Parâmetros } & Amostra Óleo & Amostra Sebo \\
\hline Umidade (\%) & 0,18 & 0,08 \\
Índice de Acidez (mg KOH/g óleo) & 1,15 & 11,98 \\
Índice de Saponificação (mg KOH/g óleo) & 201,0 & 210,0 \\
Densidade (g/mL) & 0,917744 & 0,896151 \\
\hline
\end{tabular}

Já para o sebo de boi, os dados de índice de acidez mostram que sua taxa tem um valor consideravelmente alto ao estabelecido pelas normas brasileiras para produção de biocombustível 
O estado físico a temperatura ambiente da blenda durante seu processamento é de grande importância tecnológica para avaliar a viabilidade do projeto, especialmente em operação batelada, onde, a energia será necessária em cada repetição no aquecimento e transporte de matérias-primas.

As blendas foram produzidas atravez da mistura em diferentes proporções de oleo de fritura e sebo de boi, de acordo com o procedimento já especificado na metodologia.

A temperatura ambiente determinada para o procedimento foi de $25{ }^{\circ} \mathrm{C}$ (Maringá, PR). Nessas condições as blendas com mais de $40 \%$ foram solidas. Misturas que apresentavam ponto de névoa, que é quando o primeiro sólido surge, foram descartadas (entre 29 e 39\% de sebo), pois o interesse do projeto é para as que apresentassem estado liquido apos o procedimento descrito na metodologia. Isso ocorreu com as blendas com menos de $28 \%$ de sebo, conforme representado na tabela 3 e figura 1.

Tabela 3. Proporção das blendas Óleo de fritura : Sebo bovino.

\begin{tabular}{cccc}
\hline $\begin{array}{c}\text { Proporção } \\
\text { Cocção:Sebo }\end{array}$ & Estado físico & $\begin{array}{c}\text { Proporção } \\
\text { Cocção:Sebo }\end{array}$ & Estado físico \\
\hline $24: 1$ & Líquido & $12: 13$ & Sólido \\
$23: 2$ & Líquido & $11: 14$ & Sólido \\
$22: 3$ & Líquido & $10: 15$ & Sólido \\
$21: 4$ & Líquido & $9: 16$ & Sólido \\
$20: 5$ & Líquido & $8: 17$ & Sólido \\
$19: 6$ & Líquido & $7: 18$ & Sólido \\
$18: 7$ & Líquido & $6: 19$ & Sólido \\
$17: 8$ & Pastoso & $5: 20$ & Sólido \\
$16: 9$ & Pastoso & $4: 21$ & Sólido \\
$15: 10$ & Pastoso & $3: 22$ & Sólido \\
\hline
\end{tabular}




\begin{tabular}{cccc}
\hline $14: 11$ & Sólido & $2: 23$ & Sólido \\
$13: 12$ & Sólido & $1: 24$ & Sólido \\
& & & \\
\hline
\end{tabular}

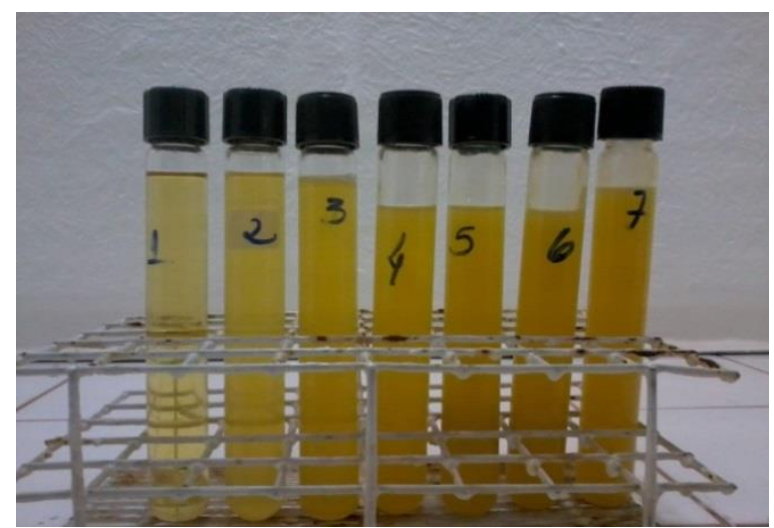

Figura 1 - Blendas líquidas.

Sabendo que o responsável pela elevação do índice de acidez na mistura é o sebo bovino, e da influência dessa variável na conversão foi efetuada a caracterização dessas blendas conforme tabela 4.

Tabela 4. Caracterização das blendas líquidas.

\begin{tabular}{lcccc}
\hline & Umidade (\%) & $\begin{array}{c}\text { Índice Acidez } \\
\text { (mg } \mathbf{K O H} / \mathbf{g} \text { óleo) }\end{array}$ & $\begin{array}{c}\text { Índice Saponificação } \\
\text { (mg } \mathbf{~} \mathbf{O H} / \mathbf{g} \text { óleo })\end{array}$ & Densidade $(\mathbf{g} / \mathbf{m l})$ \\
\hline 1 & 0,139 & 2,37 & $169,11 \pm 0,32$ & 0,892489 \\
2 & 0,140 & 2,87 & $173,79 \pm 0,24$ & 0,893112 \\
3 & 0,138 & 3,55 & $180,80 \pm 0,54$ & 0,894025 \\
4 & 0,139 & 4,50 & $179,28 \pm 0,13$ & 0,900252 \\
5 & 0,136 & 5,21 & $181,35 \pm 0,25$ & 0,911123 \\
6 & 0,137 & 6,09 & $185,93 \pm 0,43$ & 0,922187 \\
7 & 0,134 & 6,65 & $184,68 \pm 0,39$ & 0,925897 \\
\hline
\end{tabular}


Adotou-se como condição ideal para a reação química, blendas com menos de $20 \%$ de sebo Blendas 1 à 5), que resultaram em acidez inicial em torno de IA =2,37 e apresentaram densidade menor de acordo com a analise realizada. Partindo dessas, foi realizada a reação quimica para produção de esters etilico.

A evaporação, feita em rota-evaporador, após a reação retira o álcool remanescente. Sem esta operação não é possível observar a separação entre o ester e a camada de glicerina, consequentemente não conseguiriamos descobrir se ocorreu a reação com a materia-prima utilizada. $O$ uso de etanol implica maiores dificuldades no processo, tanto em relação à conversão quanto no que diz respeito a separação de fases. Mesmo assim, os resultados obtidos neste trabalho são compatíveis com a literatura.

O trabalho experimental realizado neste projeto mostra que um blendas de qualidade podem ser produzidas a partir de uma série de matéria-prima de baixo custo como os resíduos, contribuindo para redução dos custos do produto final. Comprovando assim a grande quantidade de matérias disponíveis para a produção do biocombustível, nos proporcionando alternativas viáveis que possam contribuir com o desenvolvimento sustentável, mitigando os impactos para o meio ambiente e para sociedade.

\section{CONCLUSÃO}

Uma das conclusões desde trabalho foi demonstrar que biodiesel pode ser produzido a partir de óleos de mistura, independentemente de a sua composição, fonte, e o grau de saturação da gordura.

A partir dos resultados, verificou-se que as blendas obtidas foram viáveis para a produção do biodiesel, apresentando-se uma nova materia-prima para a produção de um biocombustível que estejam dentro dos padrões de exigência e qualidade.

Enfim, a produção de blendas líquidas que tenham grande eficiência comparada aos outros tipos de matéria prima é possível. As misturas que permaneceram em estado líquido foram analisadas no cromatógrafo e apresentaram bons resultados, inclusive diminuindo o índice de acidez inicial do sebo bovino, e com características que viabilizam a produção de um biocombustível de qualidade, O biodiesel produzido atendeu por fim a 
todos os quesitos exigidos para utilização como biocombustível liquido dentro das normas nacionais, atingindo o objetivo deste trabalho. Este tipo de produção de blendas em escala industrial tem potencial para ser um investimento promissor que agrega grande valor econômico e socioambiental.

\section{REFERÊNCIAS}

CANAKCI, M; VAN GERPEN, J.; biodiesel production from oils and fats with high free fatty acids. 44.1429. 2001.

ECO 21. Biodiesel e Biomassa: duas fontes para o Brasil. Revista Eco 21, edição 80. Rio de Janeiro, RJ. Disponível em <http://www.eco21.com.br/textos/textos.asp?|D=526> Acesso em: 14 jul. 2013.

GHASSAN et al. Experimental study on evaluation and optimization of conversion of waste animal fat into biodiesel.Energy Conversion and Management, 45, 2697-271, 2004.

INSTITUTO ADOLFO LUTZ, Métodos físico-químicos para análise de alimentos. Coordenadores Odair Zenebon, Neus Sadocco Pascuet e Paulo Tiglea, 4a edição, São Paulo: Instituto Adolfo Lutz, 2008.

MAGALHÃES, FABIO CARVALHO. Blenda sebo/soja para produção de biodiesel: proposta de um processo batelada homogêneo como alternativa para agricultura familiar, 2010, dissertação (mestrado em química tecnologia e ambiental) - programa de pósgraduação em química tecnologia e ambiental, universidade federal do rio grande, rio grande, 77pinstituto adolfo lutz, Métodos físico-químicos para análise de alimentos. Coordenadores Odair Zenebon, Neus Sadocco Pascuet e Paulo Tiglea, 4a edição, São Paulo: Instituto Adolfo Lutz, 2008.

LIMA, P. C.; Biodiesel: um novo combustível para o Brasil; Brasília; Câmara dos Deputados; 2005. 
MELLO et al., Visões ambientais para o financiamento de biocombustíveis no Brasil; BNDS, 2007. 